Revista

Ibero-Americana

de Estratégıa

\title{
IDENTIFICAÇÃO DOS PRINCIPAIS AUTORES EM COOPETIÇÃO
}

\author{
IDENTIFICATION OF MAJOR AUTHORS IN COOPETITION
}

\section{IDENTIFICACIÓN DE LOS AUTORES PRINCIPALES COOPETICIÓN}

\section{Valdir Antonio Vitorino Filho}

Mestre em Administração pela Universidade Metodista de Piracicaba - UNIMEP

E-mail: valdir.vitorino@gmail.com (Brasil)

\section{Eliciane Maria da Silva}

Doutora em Engenharia de Produção pela Escola de Engenharia de São Carlos Universidade de São

Paulo - EESC/USP

E-mail: elicianems@unimep.br (Brasil)

\section{João Batista de Camargo Júnior}

Mestre em Administração pela Universidade Metodista de Piracicaba - UNIMEP

E-mail: jbcjr@uol.com.br (Brasil)

\section{Silvio Roberto Ignácio Pires}

Doutor em Engenharia de Produção pela Universidade de São Paulo - USP

E-mail: sripires@ unimep.br (Brasil) 


\title{
IDENTIFICAÇÃO DOS PRINCIPAIS AUTORES EM COOPETIÇÃO
}

\section{RESUMO}

Este artigo tem o objetivo de identificar os principais autores em coopetição por meio de duas abordagens: (a) analisar, com base em estudo bibliométrico de cocitação, a produção acadêmica em artigos disponíveis na base ISI web of knowledge sobre o tema coopetição, em 65 artigos encontrados em publicações entre 1996 e 2011; (b) identificar os autores mais citados por pesquisadores brasileiros sobre o tema coopetição, e ainda, os temas e objetos de estudos utilizados, em 26 pesquisas com publicações entre 2004 e 2012. Este estudo caracteriza-se como descritivo, com uma análise quantitativa dos dados com auxílio dos softwares Stikis ${ }^{\circ} 2.0$ e Ucinet ${ }^{\circ}$ 6.0. Os resultados demonstram que: (a) as pesquisas internacionais tiveram uma crescente no número de publicações; (b) não existem pesquisadores em nível nacional e internacional que se destacam com maior número de publicações na área; (c) foram identificados como principais autores e suas respectivas obras em coopetição: Hamel, Doz e Prahalad (1989); Nalebuff e Brandenburger (1996); Lado, Boyd e Hanlon (1997); e Bengtsson e Kock (1999 e 2000).

Palavras-chave: Autores; Bibliometria; Co-citações; Citações; Coopetição.

\section{IDENTIFICATION OF MAJOR AUTHORS IN COOPETITION}

\begin{abstract}
This article aims to identify the main perpetrators in coopetition through two approaches: (a) analyze based on bibliometric study of co-citation producing academic articles available on the ISI web of knowledge on the subject coopetition in 65 articles found in publications between 1996 and 2011, (b) identify the most cited authors by Brazilian researchers on the topic coopetition, and yet, the subjects and objects of study used in 26 research publications between 2004 and 2012. The study is characterized as descriptive and quantitative analysis of the data with the aid of software Stikis ${ }^{\circledR} 2.0$ and Ucinet ${ }^{\circledR}$ 6.0. The results show that (a) international research had in a growing number of publications, (b) there are no researchers nationally and internationally that stand out with the highest number of publications in the area, (c) have been identified as major authors and their their works in coopetition: Hamel, Doz and Prahalad (1989), Nalebuff and Brandenburger (1996); Lado, Boyd and Hanlon (1997) and Bengtsson and Kock (1999 and 2000).
\end{abstract}

Keysword: Authors; Bibliometrics; Co-citations; Citations; Coopetition. 
Valdir Antonio Vitorino Filho, Eliciane Maria da Silva, João Batista de Camargo Júnior \& Silvio Roberto Ignácio Pires

\section{IDENTIFICACIÓN DE LOS AUTORES PRINCIPALES COOPETICIÓN}

\section{RESUMEN}

Este artículo tiene como objetivo identificar los principales autores en cooperación competitiva a través de dos enfoques: (a) el análisis basado en el estudio bibliométrico de co-citación de los artículos académicos disponibles en el ISI Web of Knowledge de la cooperación competitiva tema en 65 artículos hallados en las publicaciones entre 1996 y 2011, (b) identificar los autores más citados por los investigadores brasileños en el coopetición tema, y sin embargo, los temas y objetos de estudio utilizados en 26 publicaciones de investigación entre 2004 y 2012. El estudio se caracteriza como el análisis descriptivo y cuantitativo de los datos con la ayuda de un software Stikis Ucinet $® ~ \circledR 2.0$ y 6.0. Los resultados muestran que (a) la investigación internacional tuvo un aumento en el número de publicaciones, (b) hay investigadores nacionales e internacionales destacan con mayor número de publicaciones en el área, (c) han sido identificados como los principales autores y sus sus obras en coopetición: Hamel, Doz y Prahalad (1989), Nalebuff y Brandenburger (1996), Side, Boyd y Hanlon (1997) y Bengtsson y Kock (1999 y 2000).

Palabras-clave: Autores, Bibliometría, Co-citas, citas, Coopetition. 


\section{INTRODUÇÃO}

Na dinâmica do mercado atual, são cada vez mais frequentes as fusões, aquisições e joint ventures entre empresas concorrentes. $\mathrm{O}$ ambiente empresarial sempre apresenta desafios aos seus gestores, e a concorrência entre as empresas e a busca pela posição de liderança no mercado. Mas a coopetição (competição e cooperação simultâneas entre as empresas) é um fenômeno que vem sendo estudado há pelo menos 16 anos, desde a obra intitulada "Coopetition" da autoria de Nalebuff e Brandenburger (1996), e se apresenta como uma alternativa estratégica para as organizações atingirem novos mercados, criar sinergias competitivas entre os seus participantes, alcançar novos recursos e capacidades, redução de custos com compras coletivas, desenvolvimento e planejamento conjuntos em novas tecnologias e produtos, otimização das atividades de distribuição, entre outras possibilidades.

Zineldin (2004) defende que as organizações do futuro devem, ao invés de perseguir os concorrentes convencionais, considerar os benefícios potenciais da cooperação. Argumenta que o ambiente de negócios muda a cada instante e, em razão desse dinamismo, novos tipos de relações comerciais acabam surgindo, como forma de resposta mais eficaz a essas mudanças, para fazer frente às ameaças e oportunidades ambientais. Neste contexto, a coopetição pode proporcionar a sinergia necessária para planejamento, controle e gerenciamento no alcance de resultados das organizações.

Zhang e Frazier (2011) relatam que os limites de firmas tradicionais, muitas vezes são explicados por seus custos de transação e por suas vantagens competitivas. Tal quadro, estimula que sejam estabelecidas colaborações e alianças entre diferentes empresas e diferentes mercados, em um mercado em rede de empresas. Em seus estudos, destacam a investigação sobre coopetição em uma cadeia de abastecimento entre empresas concorrentes de diferentes competências, com a formalização de um acordo contratual, para que possam um ao outro atender seus objetivos estratégicos, bem como ampliar sua participação de mercado, melhorar sua eficiência, ou entrada em um novo canal de distribuição. Ressaltam que, em alguns casos, essa relação de colaboração não se sustenta por muito tempo.

Schiavone e Simoni (2011) defendem que coopetição é o fenômeno pelo qual as empresas de um mesmo setor completam umas as outras na criação de mercado, mas competem na divisão dos mercados.

Schiavone e Simoni (2011) destacam que apesar do forte crescimento nessa corrente teórica, nos últimos quinze anos, ainda há muito que ser explorado, por exemplo, nas investigações sobre questões como P \& D (Planejamento e Desenvolvimento) e I \& D (Inovação e Desenvolvimento) 
tanto em relações intraorganizacionais como em relações interorganizacionais na rede de coopetição.

Nesse contexto, este estudo busca analisar a produção acadêmica nacional sobre o tema coopetição (os objetos de estudos utilizados, os temas relacionados) e as referências mais utilizadas para o tema em pesquisas internacionais e nacionais, com aplicação de método bibliométrico, com análises de citações e cocitações. O objetivo desta pesquisa é identificar os principais autores em coopetição, para, em seguida, direcionar os estudos de pesquisadores que têm interesse em realizar estudos nessa área. Na abrangência nacional, foram averiguados os autores mais citados; destacadas as publicações nacionais; os temas relacionados e os anos de publicação. E na abrangência internacional foram averiguados: os autores mais citados e cocitados nas referências bibliográficas, os que mais publicam sobre o tema, e os anos dessas publicações. E por fim, o artigo mostra as referências utilizadas com mais frequência em comum entre as pesquisas nacionais e internacionais.

Portanto, neste estudo, parte-se de duas questões de pesquisa relacionadas com as referências bibliográficas mais utilizadas nos estudos de coopetição, tendo o estudo como principais questionamentos: (a) quais as referências mais citadas no Brasil e no mundo em estudos sobre coopetição? (b) existe uma padronização ou homogeneidade das referências bibliográficas mais citadas em estudos de coopetição com relação a pesquisas no Brasil e no exterior?

Este estudo ainda busca investigar os seguintes pressupostos de pesquisa: (P1) há claramente alguns autores com maior número de citações para as pesquisas sobre coopetição; (P2) os pesquisadores brasileiros utilizam as mesmas citações que os pesquisadores da comunidade internacional; (P3) nas publicações internacionais, há claramente um crescente número de publicações durante a evolução dos anos; e (P4) nas pesquisas internacionais e nacionais existe claramente autores com maior número de publicações na área.

O trabalho está estruturado da seguinte forma: na seção 2, são apresentadas as definições e contextualizações sobre coopetição e alguns dos modelos mais usuais; na seção 3, a metodologia da pesquisa, bem como as categorias de análise; na seção 4 , as discussões que permeiam a pesquisa acerca dos levantamentos bibliométricos em nível Brasil e mundial; na seção 5, as considerações finais do estudo, e por fim, as referências bibliográficas utilizadas ao longo da pesquisa. 


\section{COOPETIÇÃO}

Para Bengtsson e Kock (2000, p. 413), coopetição "é a relação diádica e paradoxal que emerge quando duas empresas cooperam em alguma atividade, como em uma aliança estratégica, e ao mesmo tempo competem uns com os outros em outras atividades".

Zineldin (2004, p. 782) define coopetição como sendo “uma situação de negócio em que partes independentes cooperam entre si e coordenam as suas atividades, assim colaborando para atingir objetivos em comum, mas ao mesmo tempo competindo uns com os outros". A base dessas relações comerciais deve ser a de parceria mútua entre as atividades de gestão industrial, incluindo os concorrentes. Com o intuito de criar e desenvolver processos de cooperação que irão reforçar as relações de longo prazo, a retenção e a lealdade.

Ressalta Yadong (2007) que áreas funcionais são propensas a cenários de co-petição, como por exemplo, terceirização, acordos de fornecimentos, co-produção, atividades da cadeia de valores, como P\&D (Planejamento e Desenvolvimento), sistemas de informação, e ainda, conhecimentos de gestão. E que a coopetição em mercados globais é fortalecida quando existem assimetrias de recursos entre os concorrentes globais.

A coopetição é uma estratégia desafiadora que exige das empresas e de seus gestores que reformulem suas complexas estratégias de competição e alinhem com uma cooperação de boa fé, e possam competir para melhorar seus próprios resultados estratégicos. (GNYAWALI e PARK, 2009).

Schoo (2009) acredita que coopetição é uma rede de atores que interagem entre si cooperando ou competindo, para a criação de um maior valor (ou ainda, criando um máximo valor), tornando-se uma das mais importantes estratégias de negócios nos últimos anos. Lin, et. al. (2010) propõem em seus estudos que a formação da eficácia no trabalho é diretamente influenciada pela partilha de conhecimento, à atitude de cooperação e o conflito competitivo.

A seguir o artigo apresenta, de forma sintética, o que se acredita, ser os cinco mais importantes modelos teóricos para análise de coopetição: (1) a rede de valores (Nalebuff e Brandenburger, 1996); (2) modelo de comportamento rent-seeking (Lado, Boyd e Hanlon, 1997); (3) diferentes tipos de relações de coopetição entre concorrentes (Bengtsson e Kock, 2000); (4) o framework da tipologia da coopetição (Garraffo, 2002); e (5) o nível da cadeia de valor e o número de firmas (Dagnino e Padula, 2002).

Para Nalebuff e Brandenburger (1996) a rede de valores é composta por duas dimensões: a vertical e a horizontal. Na dimensão vertical destacam-se os fregueses e os fornecedores, e na 
Valdir Antonio Vitorino Filho, Eliciane Maria da Silva, João Batista de Camargo Júnior \& Silvio Roberto Ignácio Pires

dimensão horizontal encontram-se os concorrentes e os complementadores, como demonstra a Figura 1.

Segundo Nalebuff e Brandenburger (1996) um complementador pode ser uma pessoa, instituição, ou qualquer jogador que faça com que seus fregueses valorizem mais o seu produto quando eles têm o produto do complementador do que quando tem o seu produto em separado. Já os concorrentes fazem com que os fregueses valorizam menos o produto de sua companhia quando os fregueses têm o produto do concorrente do que quando têm o produto da companhia isoladamente. Exemplo: a venda de chips da Intel aumenta quando a Microsoft cria softwares mais potentes.

Figura 1 - A Rede de Valores

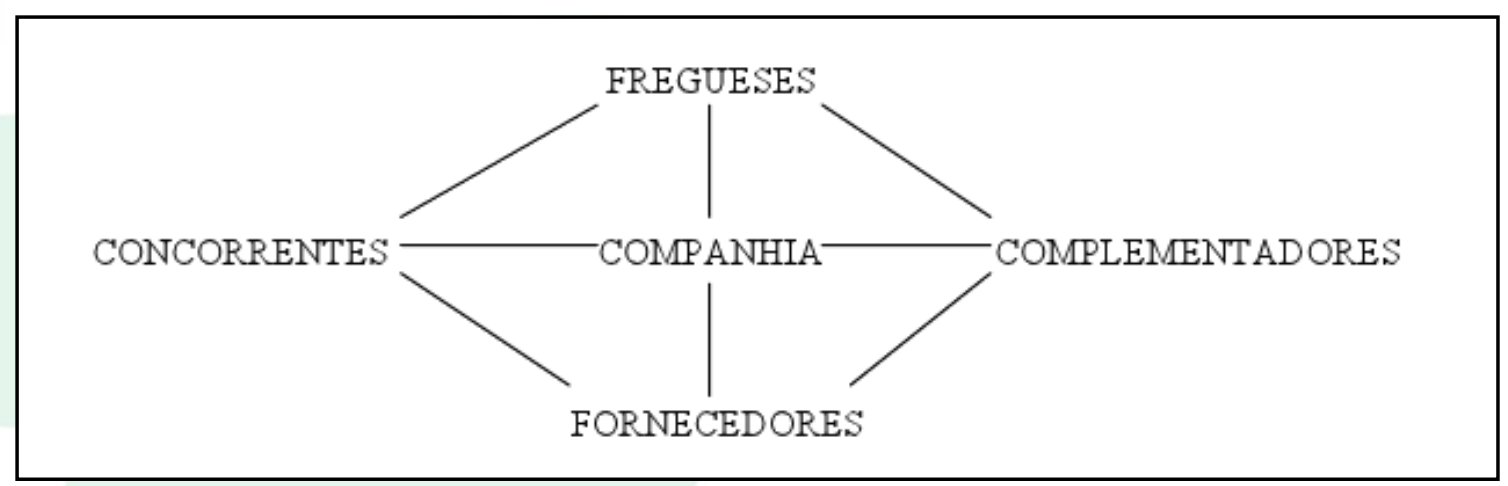

Fonte: Adaptado de Nalebuff e Brandenburger (1996).

Lado, Boyd e Hanlon (1997) propõem um modelo de comportamento baseado em rentseeking (a busca por recursos e "capabilidades" externas a organização que proporcionem a obtenção de retornos econômicos acima da média do mercado). Para o modelo as empresas podem ter orientação voltada para cooperação e orientação voltada para competição, formando quatro possibilidades: (a) a baixa orientação cooperativa e também baixa orientação competitiva, esse situação levaria um comportamento rent-seeking monopolista; (b) a baixa orientação cooperativa e alta orientação competitiva, de comportamento rent-seeking competitivo; (c) a alta orientação cooperativa e também alta orientação competitiva, voltada para um comportamento rent-seeking de "sincretismo"; e (d) a alta orientação cooperativa e baixa orientação competitiva, acabem gerando um comportamento rent-seeking colaborativo. Como na Figura 2. 
Figura 2 - Modelo de Comportamento Rent-Seeking

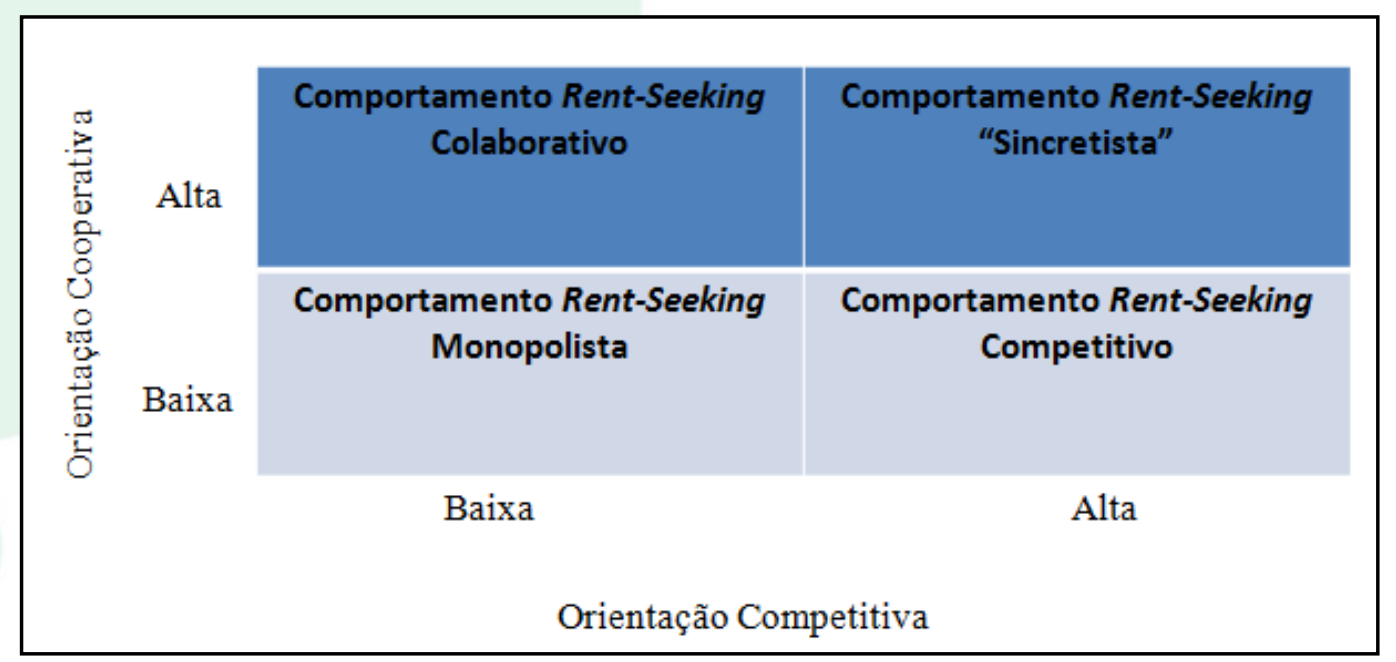

Fonte: Adaptado de Lado, Boyd e Hanlon (1997).

Bengtsson e Kock (2000) reforçam a ideia com o seguinte agumento: que o trade-off entre a cooperação e competição entre empresas pode ser a possibilidade da criação de progresso entre as empresas envolvidas, com um relacionamento de longo prazo. Mas as contribuições de Bengtsson e Kock (2000) concentram-se no trade-off entre cooperação e competição nas relações dos mesmos com a concorrência. E ainda que existem fortes semelhanças entre as empresas, nas relações verticais e horizontais, por exemplo, podem existir tipos totalmente distintos de relacionamentos e estruturas entre as empresas, e que para esses casos o trade-off nas relações de cooperação serão diferentes, por isso, devem ser geridos de formas diferentes. Com os três tipos de relacionamentos: dominante em cooperação, equilibrado e dominante em competição, como na Figura 3.

Para Bengtsson e Kock (2000) as empresas tendem a cooperar em atividades realizadas em uma distância maior de seus clientes, e a competir em atividades mais próximas para os clientes. 
Valdir Antonio Vitorino Filho, Eliciane Maria da Silva, João Batista de Camargo Júnior \& Silvio Roberto Ignácio Pires

Figura 3 - Diferentes tipos de relações de coopetição entre concorrentes

Relacionamento dominante em cooperação: a coopetição consiste em mais cooperaçäo do que competição.

Relacionamento equilibrado: cooperaçäo e competiçäo são igualmente distribuidas.

Relacionamento dominante em competição: a coopetição consiste em mais competiçäo do que cooperação.

Fonte: Adaptado de Bengtsson e Kock (2000).

Em seu modelo Garraffo (2002) apresenta os níveis de compromisso na criação de mercados com relação aos níveis de compromisso sobre a evolução tecnológica, onde esses níveis podem ser altos e baixos, como na Figura 4. Nesta figura, para baixo compromisso na criação de mercados e baixo compromisso na evolução tecnológica existe uma troca de conhecimento entre as empresas. Se o nível de compromisso na criação de mercados for alto e o nível de comprimisso em evolução tecnológica for baixo, têm-se uma fixação de padrões. Já para altos níveis tanto na criação de mercados e evolução tecnológica um comportamento de integração dos negócios. E por fim, um baixo nível de compromisso na criação de mercados e alto nível de compromisso na evolução tecnológica proporcionam uma cooperação em P\&D.

Figura 4 - A tipologia de coopetição

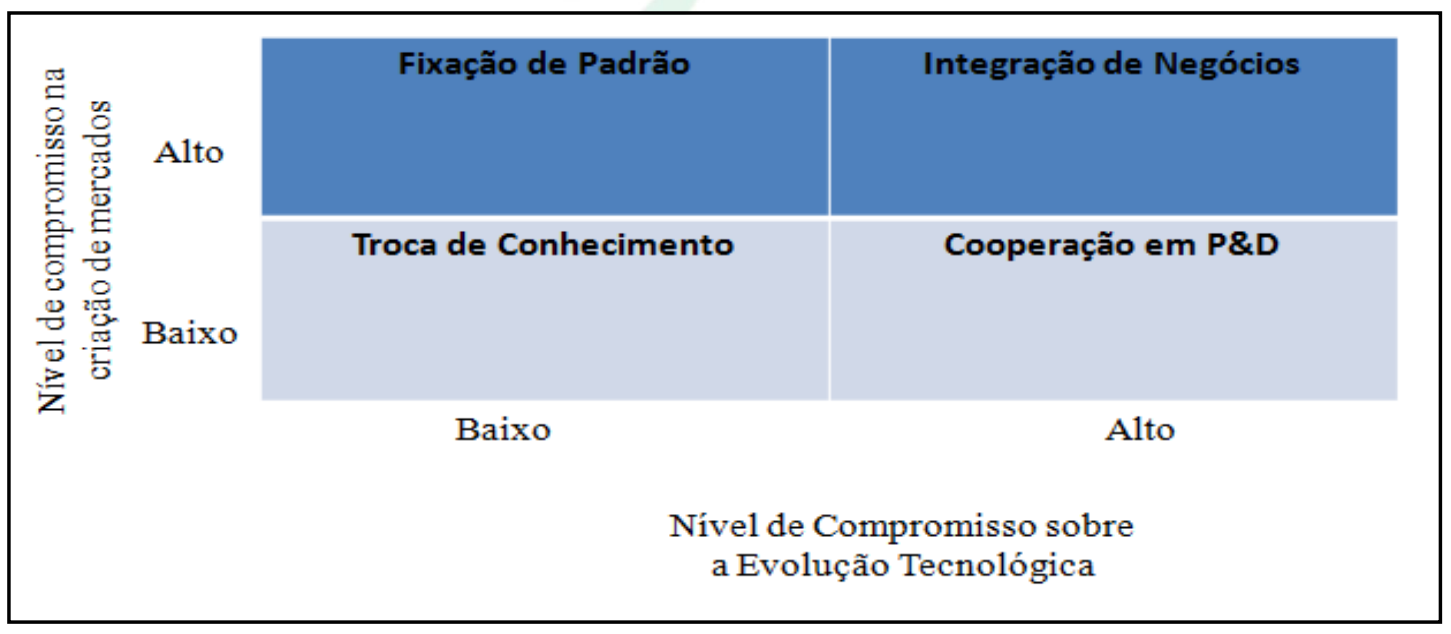

Fonte: Adaptado de Garraffo (2002). 
Já no modelo de Dagnino e Padula (2002), averigua-se a relação entre os níveis da cadeia de valor com relação ao número de firmas envolvidas, como demonstrado na Figura 5. Dagnino e Padula (2002) formulam três conclusões principais em seus estudos: (a) a interdependência das empresas é tanto uma fonte de criação de valor econômico quanto um lugar para a partilha de valor econômico; (b) a interdependência das empresas é baseada em um jogo variável de soma positiva que pode trazer benefícios mútuos, mas não necessariamente justo para os parceiros por causa de várias pressões competitivas de natureza diferente, que pode comprometer sua estrutura coopetitiva; e (c) em uma estrutura de jogo variável de soma, a interdependência da empresa baseia-se em uma função parcialmente convergente de interessse das interfirmas.

Figura 5 - O modelo dos níveis da cadeia de valor e o número de firmas

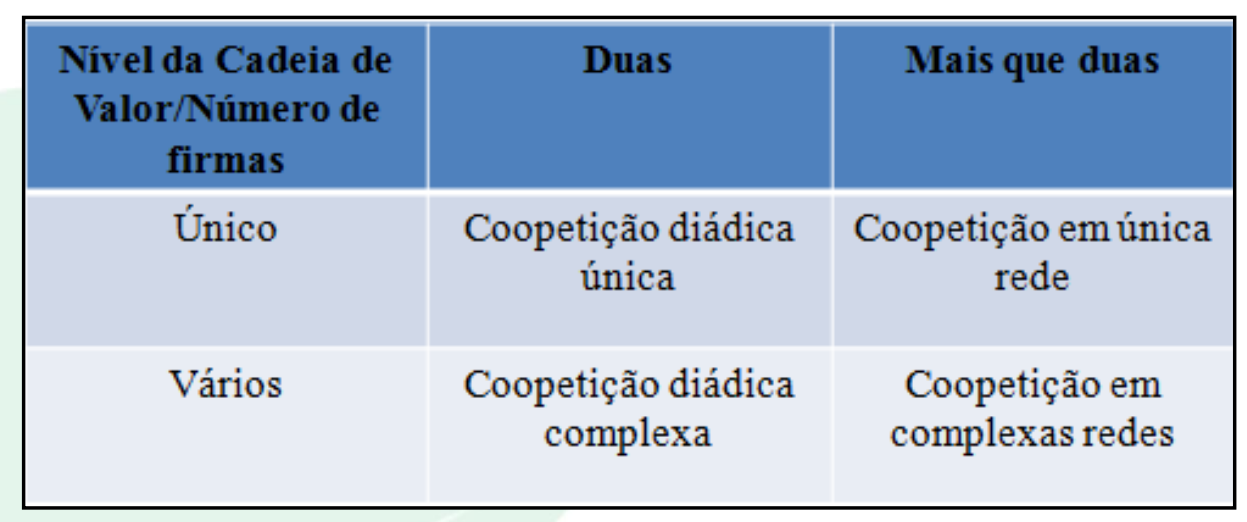

Fonte: Adaptado de Dagnino e Padula (2002).

Para Schiavone e Simoni (2011), o fenômeno da coopetição ocorre mais comumente em indústrias maduras ou de alta tecnologia, em que as competitividades e as posições no mercado são difíceis de serem mantidas ou de se obter uma liderança monopolista. E ainda, que a coopetição pode surgir tanto em empresas com um nível de relação individual ou em nível de rede de empresas, e também nos níveis de cadeias de valor.

Para Zhang e Frazier (2011), as relações de concorrência têm sido consideradas como as políticas de preços adotadas pelas empresas, mas propõem que mesmo em setores econômicos muito competitivos, a relação de coopetição pode existir como uma forma de relação interfirmas. Nessa relação, a empresa pode contratar uma empresa para realizar uma, ou algumas, de suas funções de negócios, que são considerados pontos fracos, para ganhar em eficiência, ao invés de administrar e realizar tudo sozinha. Exemplo: A aliança entre Yahoo e Microsoft para usar a opção de busca Bing, mas vão competir para vender anúncios de busca. 


\section{ABORDAGEM METODOLÓGICA E MÉTODOS DA PESQUISA}

Esta pesquisa caracteriza-se como um estudo bibliométrico (uma análise estatística de registros bibliográficos), com análise de citações (baseia-se na contagem direta feita em outros documentos) e cocitações (explora as citações emparelhadas como uma medida de associação entre os autores). (Pritchard, 1969). A pesquisa é de caráter descritivo (caracterizado pelo comportamento dos fenômenos, para obter informações sobre características de uma determinada área) e quantitativo (um método de pesquisa que utiliza técnicas estatísticas). (Collins e Hussey, 2005).

Optou-se em dividir a pesquisa em duas partes: a primeira parte foi realizada em nível internacional, tendo como base a coleta de dados dos artigos disponíveis no ISI Web of Knowledge, via <http://isiwebofknowledge.com> sobre o tema: coopetição. Nessa busca, foi delimitado um período de tempo de 15 anos (1996-2011), com palavra-chave em inglês "coopetition”, busca realizada nos títulos, resumos e palavras-chave dos artigos. O tratamento aos dados ocorreu com o emprego de técnicas da bibliometria, para determinar quais dos autores foram mais citados e cocitados entre as referências bibliográficas.

Para a pesquisa em nível internacional, a busca obteve 65 artigos, sendo a totalidade utilizada como objeto de estudo para essa pesquisa. Ressalta-se que foram encontradas 227 citações diferentes nas referências bibliográficas.

Em uma primeira etapa, utilizou-se o software Sitkis 2.0 para coleta dos artigos e tratamento das referências bibliográficas (quantidade de citações). Em segunda etapa, utilizou-se o software Ucinet $^{\circ} 6.0$ para análise de cocitação entre os autores que constavam nas referências bibliográficas, sendo que foi estabelecido um mínimo de 5 citações para cada um dos autores, o que resultou um total de 23 autores.

Na segunda parte da pesquisa, foi realizada uma análise de textos publicados em português disponíveis no site de busca Google Acadêmico via <http://scholar.google.com.br/>, com a palavra “coopetição", pesquisada nos títulos, subtítulos, resumos e palavras-chave dos artigos encontrados.

Para a pesquisa em nível Brasil foram selecionados 26 textos (dissertações, artigos em anais de congressos e artigos em revistas eletrônicas), sendo a totalidade utilizada para a contagem de citações nas referências bibliográficas, com um total de 1.106 citações, sendo 756 citações diferentes. 


\subsection{CATEGORIAS PARA ANÁLISE}

Na pesquisa em nível internacional foram identificadas algumas características, tais como: os autores que mais publicam nessa área; o país de origem da publicação dos artigos; o ano de publicação; e ainda quais foram os autores mais citados e cocitados nas referências bibliográficas desses 65 artigos.

Na pesquisa em nível Brasil foram analisados: os autores que publicaram os textos, o ano de publicação, as instituições as quais esses autores estavam vinculados na época da publicação, os temas relacionados e os objetos de estudos utilizados e o meio de divulgação dessas pesquisas (artigos em revistas online, dissertações, anais de congressos); e ainda os autores mais citados nas referências bibliográficas dos 26 textos. E por fim, relacionam-se os autores mais citados, tanto nos textos internacionais quanto nos textos publicados no Brasil.

\section{RESULTADOS DA PESQUISA}

A seguir são apresentados os resultados obtidos pela pesquisa bibliométrica, levando em consideração as categorias de análise listadas anteriormente.

\subsection{PESQUISA EM NÍVEL INTERNACIONAL}

No Quadro 1 são apresentados os autores que mais publicaram dentre os artigos analisados, sendo dois autores (Eriksson, Per-Erik e Luo, Y.) com três artigos publicados; e três autores (Hurmellinna, Laukkanen Pia; Ritala, Paavo e Rusko, Rauno) com dois artigos publicados cada. Com os demais autores tendo publicado apenas um artigo sobre o tema coopetição. 
Valdir Antonio Vitorino Filho, Eliciane Maria da Silva, João Batista de Camargo Júnior \& Silvio Roberto Ignácio Pires

\begin{tabular}{|l|c|c|}
\hline \multicolumn{1}{|c|}{ AUTORES } & QTDE & $\%$ \\
\hline Eriksson, Per-Erik & 3 & 4,62 \\
\hline Luo, Y & 3 & 4,62 \\
\hline Hurmellinna, Laukkanen Pia & 2 & 3,08 \\
\hline Ritala, Paavo & 2 & 3,08 \\
\hline Rusko, Rauno & 2 & 3,08 \\
\hline
\end{tabular}

Quadro 1 - Publicação por autores Fonte: Elaborado pelos autores.

O Quadro 2 apresenta os países de origem dos artigos publicados. Os Estados Unidos é o país que detêm maior número de publicações (18), seguido de China (7), Taiwan (6), Finlândia, Holanda e Suécia (5 cada), Inglaterra (4), Itália, Polônia (3 cada) e Polônia, Austrália (2 cada), demais países aparecem apenas uma vez e totalizam 7 artigos.

\begin{tabular}{|l|c|c|}
\hline \multicolumn{1}{|c|}{ PAÍS } & QTDE & $\%$ \\
\hline Estados Unidos & 18 & 27,69 \\
\hline China & 7 & 10,77 \\
\hline Taiwan & 6 & 9,23 \\
\hline Finlândia & 5 & 7,69 \\
\hline Holanda & 5 & 7,69 \\
\hline Suécia & 5 & 7,69 \\
\hline Inglaterra & 4 & 6,15 \\
\hline Itália & 3 & 4,62 \\
\hline Polônia & 3 & 4,62 \\
\hline
\end{tabular}


Identificação dos Principais Autores em Coopetição

\begin{tabular}{|l|c|c|}
\hline Austrália & 2 & 3,08 \\
\hline Demais Países & 7 & 10,77 \\
\hline
\end{tabular}

Quadro 2 - Países de origem dos artigos

Fonte: Elaborado pelos autores.

Averigua-se no Gráfico 1 que os anos em que se concentraram mais publicações foram 2009 e 2011 com doze publicações cada ano, ainda 2008 com nove publicações, 2007 com seis, 2010 com seis, o ano de 2005 com cinco publicações e, por fim, 2006 com quatro publicações. Demais anos tiveram apenas uma ou nenhuma publicação.

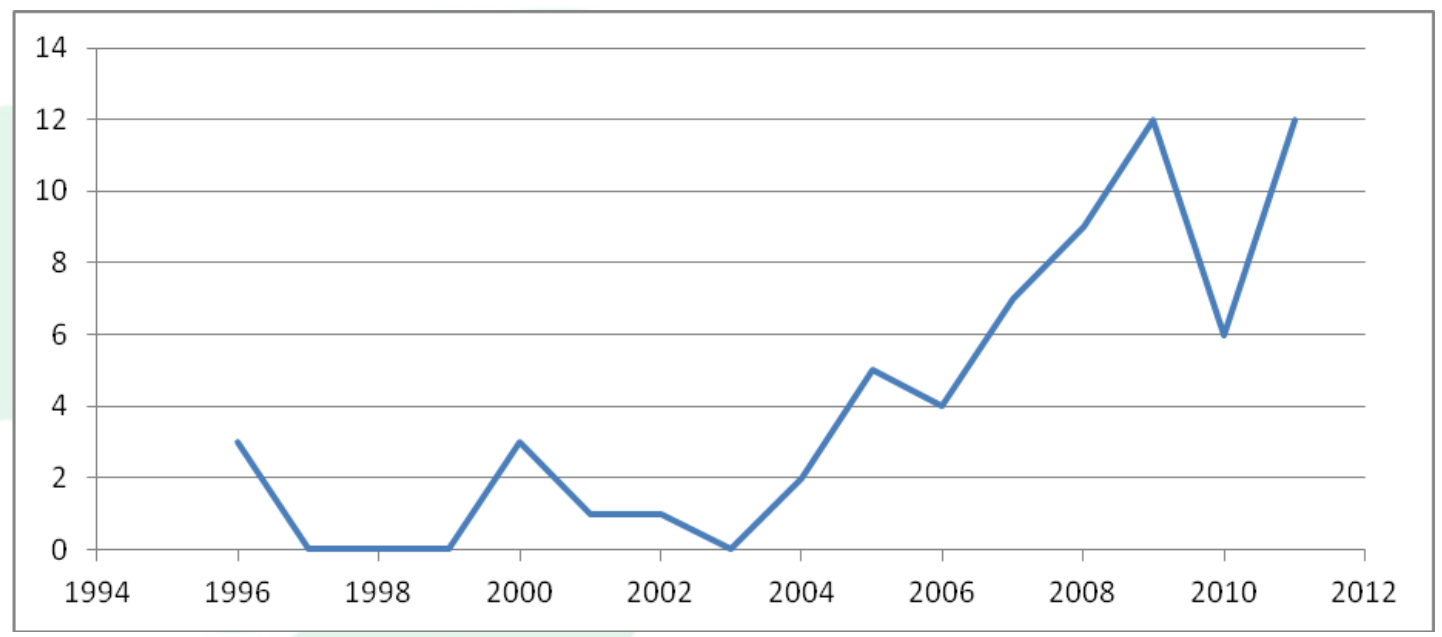

Gráfico 1 - Publicações por ano Fonte: Elaborado pelos autores.

\subsection{AUTORES MAIS CITADOS E CO-CITADOS}

Os autores que aparecem com maior número de citações, e as suas relações de cocitações, levando em consideração um número mínimo de cinco cocitações cada, são: Barney, J., J. (1991); Bengtsson, M., J. e Kock, S. (1999); Brandenburger, A., M. e Nalebuff, B., J. (1995); Bengtsson, M. e Kock, S. (2000); Chen, M., J. (1996); Dyer, J., H. e Singh, H. (1998); Granovetter, M. (1985); Gnyawali, D., R. e Madhavan, R. (2001); Hamel, G.; Doz, Y., L. e Prahalad, C., K. (1989); Hamel, G. (1991); Khanna, T., Gulati, R. e Nohria, N. (1998); Luo, Y. D. (2004); Lado, A. A.; Boyd, N. G. e Hanlon, S. C. (1997); Luo, X., M. (2006); Luo, Y., D. (2005); Morgan, R., M. (1994); Pfeffer, J. e 
Valdir Antonio Vitorino Filho, Eliciane Maria da Silva, João Batista de Camargo Júnior \& Silvio Roberto Ignácio Pires

Salancik, G. (1978); Quintana-Garcia, C. e Benavides-Velasco, C., A. (2004); Tsai, W., P. (2002); Uzzi, B. (1997); Walley, K. (2007) e Williamson, O., E. (1985). Como demonstrado na Figura 6.

Figura 6 - Referências mais Co-citadas sobre o tema coopetição

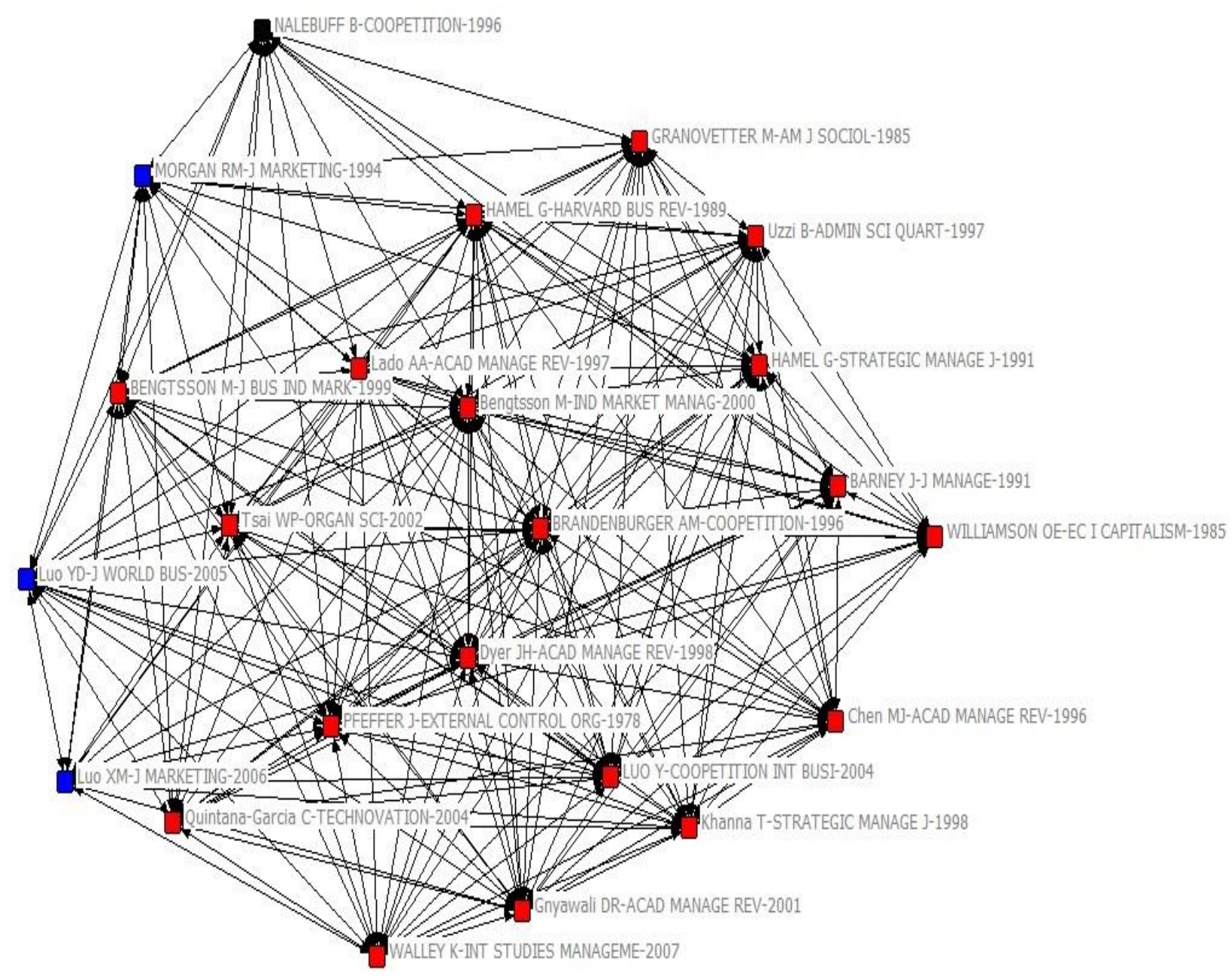

Fonte: Dados gerados pelo software Ucinet ${ }^{\circledR}$.

Predominam como temas abordados nas referências bibliográficas relacionadas ao termo coopetition: a visão baseada em recursos - os recursos que agregam valor, raros, imperfeitamente imitáveis e substituibilidade (Barney, 1991); os diferentes tipos de relações de coopetição entre concorrentes - relacionamento dominante em cooperação, relacionamento equilibrado e 
relacionamento dominante em competição (Bengtsson e Kock, 1999 e 2000); a ideia da rede de valores - concorrentes, complementadores, fornecedores e clientes (Brandenburger e Nalebuff, 1996); análise da concorrência e da rivalidade interfirmas (Chen, 1996); a visão relacional na cadeia de suprimentos (Dyer e Singh, 1998); o impacto da estrutura social na economia (Granovetter, 1985); as redes de cooperação e a dinâmica competitiva (Gnyawali e Madhavan, 2001); as alianças estratégicas (Hamel, Doz e Prahalad, 1989); aprendizagem dentro das alianças estratégicas internacionais (Hamel, 1991); a dinâmica da aprendizagem em alianças (Khanna, Gulati e Nohria, 1998); a exploração das capacidades em mercados internacionais (Luo, 2004 e 2005); o modelo de comportamento rent-seeking (Lado, Boyd e Hanlon, 1997); a teoria da confiança e compromisso nos relacionamentos de marketing (Morgan, 1994); a abordagem da dependência de recursos (Pfeffer e Salancik, 1978); a capacidade de inovação em empresas de biotecnologia (QuintanaGarci e Benavides-Velasco, 2004); a estrutura social de coopetição dentro de uma organização (Tsai, 2002); a estrutura social em redes de empresas (Uzzi, 1997); a colaboração para redução do impacto ambiental - “eco-copeitção" (Walley, 2007); e a dependência de recursos e a economia das instituições (Williamson, 1985).

\subsection{PESQUISA EM NÍVEL BRASIL}

A seguir, são apresentadas pesquisas desenvolvidas pela academia brasileira com o uso da coopetição, seus respectivos autores, anos de publicação, as instituições de ensino as quais os autores possuem vínculo, os temas relacionados aos estudos, os objetos de estudo utilizados para análise de coopetição e o local onde os textos foram publicados. Para mais detalhes ver Quadro 3.

\begin{tabular}{|c|c|l|l|c|}
\hline AUTORES & INSTITUIÇÃo & $\begin{array}{c}\text { TEMAS } \\
\text { ASSOCIADOS }\end{array}$ & $\begin{array}{c}\text { OBJETO DE } \\
\text { ESTUDO }\end{array}$ & PUBLICAÇÃo \\
\hline Leão (2004) & UFPE & $\begin{array}{l}\text { Rede de Valores. } \\
\text { Impacto nas variáveis } \\
\text { de desempenho } \\
\text { (vendas, lucratividade, } \\
\text { preço, produção, } \\
\text { produtividade) }\end{array}$ & $\begin{array}{l}\text { Indústria de cachaça } \\
\text { de alambique em } \\
\text { Minas Gerais }\end{array}$ & Dissertação de Mestrado \\
\hline Leão (2005) & UFPE & $\begin{array}{l}\text { Modelos Teóricos de } \\
\text { Coopetição }\end{array}$ & Não Aplica & 3 E's - ANPAD \\
\hline
\end{tabular}


Valdir Antonio Vitorino Filho, Eliciane Maria da Silva, João Batista de Camargo Júnior \& Silvio Roberto Ignácio Pires

\begin{tabular}{|c|c|c|c|c|}
\hline $\begin{array}{c}\text { Costa, Bottura, } \\
\text { Boaventura e } \\
\text { Fischmann }(2006)\end{array}$ & USP e UNICAMP & $\begin{array}{l}\text { Matriz de Jogos } \\
\text { Estratégicos. } \\
\text { Minimax, Nash, } \\
\text { Pareto e Stackelberg }\end{array}$ & Intel Corporation & EnANPAD \\
\hline Gollo (2006) & UFRGS & Processo de Inovação. & $\begin{array}{l}11 \text { vinícolas em } \\
\text { Serra Gaúcha/RS }\end{array}$ & EnANPAD \\
\hline $\begin{array}{l}\text { Azevedo e Matos } \\
\quad \text { (2006) }\end{array}$ & UFPE & $\begin{array}{l}\text { Poder de barganha } \\
\text { com fornecedor, } \\
\text { compartilhamento de } \\
\text { tecnologia }\end{array}$ & $\begin{array}{l}\text { Valexport no Vale } \\
\text { do São Francisco }\end{array}$ & SIMPEP \\
\hline $\begin{array}{l}\text { Sauaia e Kallás } \\
\text { (2007) }\end{array}$ & USP & $\begin{array}{l}\text { Jogos de Empresa. As } \\
\text { cinco forças } \\
\text { competitivas e a Rede } \\
\text { de Valor. }\end{array}$ & $\begin{array}{l}\text { Simulação } \\
\text { Empresarial em um } \\
\text { Jogo de Empresas }\end{array}$ & $\begin{array}{l}\text { RAC - Revista de } \\
\text { Administração } \\
\text { Contemporânea }\end{array}$ \\
\hline $\begin{array}{c}\text { Rodrigues, } \\
\text { Maccari e } \\
\text { Riscarolli (2007) }\end{array}$ & UNINOVE & $\begin{array}{l}\text { Rede de Valor } \\
\text { (fornecedores, } \\
\text { produtores, cliente, } \\
\text { parceria em P\&D e } \\
\text { suporte) }\end{array}$ & $\begin{array}{l}\text { Rede } \\
\text { Interorganizacional } \\
\text { da Cia. Hering }\end{array}$ & $\begin{array}{l}\text { Revista de Gestão da } \\
\text { Tecnologia e Sistemas de } \\
\text { Informação }\end{array}$ \\
\hline $\begin{array}{l}\text { Rennó e Judice } \\
\text { (2008) }\end{array}$ & $\begin{array}{l}\text { Faculdade Novos } \\
\text { Horizontes e UFSJ }\end{array}$ & $\begin{array}{l}\text { Uso da marca, suporte } \\
\text { em marketing, } \\
\text { fornecimento de } \\
\text { materiais e know how }\end{array}$ & $\begin{array}{l}3 \text { franquias de uma } \\
\text { rede de escolas de } \\
\text { idiomas em Minas } \\
\text { Gerais }\end{array}$ & $\begin{array}{c}\text { Revista de Administração da } \\
\text { FEAD Minas }\end{array}$ \\
\hline $\begin{array}{l}\text { Melo, Câmara, } \\
\text { Galindo, Capelo } \\
\text { Jr e Rocha (2008) }\end{array}$ & UECE & $\begin{array}{l}\text { Investimentos em } \\
\text { P\&D }\end{array}$ & $\begin{array}{l}23 \text { empresas de TIC } \\
\text { do Ceará }\end{array}$ & EnANPAD \\
\hline $\begin{array}{c}\text { Marchi e } \\
\text { Wittmann (2008) }\end{array}$ & UFPel e UFSM & $\begin{array}{l}\text { Redes de Empresa, } \\
\text { Desempenho } \\
\text { Competitivo e Fatores } \\
\text { Sócio- } \\
\text { Comportamentais }\end{array}$ & $\begin{array}{l}\text { Duas redes de } \\
\text { supermercados, a } \\
\text { Central Mais } \\
\text { ( } 33 \text { empresas) e a } \\
\text { rede Unimercados } \\
\text { (17 empresas) }\end{array}$ & REAd \\
\hline $\begin{array}{l}\text { Gollo e Castro } \\
\text { (2008) }\end{array}$ & UFRGS & $\begin{array}{l}\text { Aumento da } \\
\text { competitividade e } \\
\text { implantação de } \\
\text { inovação }\end{array}$ & $\begin{array}{l}\text { Vinícola Boutique } \\
\text { Lidio Carraro-Serra } \\
\text { Gaúcha/RS }\end{array}$ & $\begin{array}{c}\text { Congresso da Sociedade } \\
\text { Brasileira de Economia, } \\
\text { Administração e Sociologia } \\
\text { Rural }\end{array}$ \\
\hline $\begin{array}{l}\text { Gollo, Setubal, } \\
\text { Cruz, Winckler e } \\
\text { Rodrigues (2008) }\end{array}$ & UPF/RS & $\begin{array}{l}\text { Implementação de } \\
\text { Inovações de produto, } \\
\text { processo, distribuiçãao } \\
\text { e gestão } \\
\text { organizacional }\end{array}$ & $\begin{array}{l}\text { Vinícola Valduga- } \\
\text { Serra Gaúcha/RS }\end{array}$ & $\begin{array}{c}\text { Congresso da Sociedade } \\
\text { Brasileira de Economia, } \\
\text { Administração e Sociologia } \\
\text { Rural }\end{array}$ \\
\hline
\end{tabular}


Identificação dos Principais Autores em Coopetição

\begin{tabular}{|c|c|c|c|c|}
\hline Selotti Jr (2008) & FGV/SP & $\begin{array}{l}\text { Alianças Estratégias. } \\
\text { Sensemaking (criação } \\
\text { de sentido). } \\
\text { Complementariedade }\end{array}$ & $\begin{array}{l}\text { Aliança entre TAM } \\
\text { e Varig / Joint } \\
\text { Venture Itaú, } \\
\text { Unibanco e Citibank }\end{array}$ & Dissertação de Mestrado \\
\hline Melo (2009) & UNIFOR & $\begin{array}{l}\text { As cinco forças } \\
\text { competitivas e a Rede } \\
\text { de Valor }\end{array}$ & $\begin{array}{l}\text { A Rede de Valor da } \\
\text { Greendene S/A }\end{array}$ & Dissertação de Mestrado \\
\hline $\begin{array}{l}\text { Leite, Lopes e } \\
\text { Silva (2009) }\end{array}$ & PUC/MG & $\begin{array}{l}\text { Troca de informações } \\
\text { e Alocação de } \\
\text { Insumos }\end{array}$ & $\begin{array}{l}\text { APL - Calçadista de } \\
\text { Nova Serrana }\end{array}$ & Rev. Bras. Gestão e Negócios \\
\hline Neves (2009) & PUC/RS & $\begin{array}{l}\text { Confiança, } \\
\text { complementariedade, } \\
\text { adaptabilidade, troca } \\
\text { de experiência e } \\
\text { aprendizagem }\end{array}$ & $\begin{array}{l}\text { Redes Agafarma e } \\
\text { Redecore no Rio } \\
\text { Grande do Sul }\end{array}$ & Dissertação de Mestrado \\
\hline Alves (2010) & EBAPE/FGV & Administração Pública & Estado Brasileiro & Revista ADM. MADE \\
\hline Winckler (2010) & UFRGS & $\begin{array}{l}\text { Rede de Valor. Cadeia } \\
\text { Produtiva (clientes, } \\
\text { competidores, } \\
\text { fornecedores e } \\
\text { complementadores) }\end{array}$ & $\begin{array}{l}\text { Produtores de Leite } \\
\text { da Rede Ascooper } \\
\text { no Oeste de Santa } \\
\text { Catarina }\end{array}$ & Dissertação de Mestrado \\
\hline $\begin{array}{c}\text { Winckler, } \\
\text { Brandão e } \\
\text { Machado (2010) }\end{array}$ & UFRGS & $\begin{array}{l}\text { Rede de Valor. Cadeia } \\
\text { Produtiva (clientes, } \\
\text { competidores, } \\
\text { fornecedores e } \\
\text { complementadores) }\end{array}$ & $\begin{array}{l}\text { Propriedade Rural } \\
\text { Familiar no Oeste de } \\
\text { Santa Catarina }\end{array}$ & $\begin{array}{c}\text { Congresso da Sociedade } \\
\text { Brasileira de Economia, } \\
\text { Administração e Sociologia } \\
\text { Rural }\end{array}$ \\
\hline $\begin{array}{l}\text { Oliveira, Marins e } \\
\text { Rocha (2011) }\end{array}$ & FEG-UNESP & $\begin{array}{l}\text { Competências } \\
\text { Essenciais e } \\
\text { Prioridades } \\
\text { Competitivas }\end{array}$ & $\begin{array}{l}\text { Consórcio Modular } \\
\text { da Volkswagem } \\
\text { Caminhões e Ônibus } \\
\text { do Brasil }\end{array}$ & ENEGEP \\
\hline $\begin{array}{c}\text { Winckler e } \\
\text { Molinari (2011) }\end{array}$ & UFRGS & $\begin{array}{l}\text { Conceitos em } \\
\text { Estratégias } \\
\text { Interorganizacionais }\end{array}$ & Não aplica & $\begin{array}{l}\text { Revista ADMpg Gestão } \\
\text { Estratégica }\end{array}$ \\
\hline $\begin{array}{c}\text { Petter, Vaz, } \\
\text { Resende e } \\
\text { Francisco (2011) }\end{array}$ & UTFPR e UFSC & $\begin{array}{l}\text { Dimensões Estruturais } \\
\text { de uma Rede (Níveis } \\
\text { Micro, Meso e Macro) }\end{array}$ & $\begin{array}{l}\text { Redes } \\
\text { Interorganizacionais } \\
\text { de MPE's }\end{array}$ & $\begin{array}{l}\text { Congresso Internacional de } \\
\text { Administração }\end{array}$ \\
\hline $\begin{array}{c}\text { Neves, Diehl, } \\
\text { Hansen e Becker } \\
(2011)\end{array}$ & $\begin{array}{l}\text { PUC/RS e } \\
\text { UNISINOS }\end{array}$ & $\begin{array}{l}\text { Confiança, } \\
\text { complementariedade, }\end{array}$ & $\begin{array}{l}\text { Redes Agafarma e } \\
\text { Redecore no Rio } \\
\text { Grande do Sul }\end{array}$ & $\begin{array}{l}\text { Revista de Administração e } \\
\text { Contabilidade da Unisinos }\end{array}$ \\
\hline
\end{tabular}


Valdir Antonio Vitorino Filho, Eliciane Maria da Silva, João Batista de Camargo Júnior \& Silvio Roberto Ignácio Pires

\begin{tabular}{|c|c|c|c|c|}
\hline & & $\begin{array}{l}\text { adaptabilidade, troca } \\
\text { de experiência e } \\
\text { aprendizagem }\end{array}$ & & \\
\hline $\begin{array}{l}\text { Zampese e Zilber } \\
\text { (2011) }\end{array}$ & $\begin{array}{l}\text { Universidade } \\
\text { Presbiteriana } \\
\text { Mackenzie }\end{array}$ & $\begin{array}{l}\text { Redução de custos } \\
\text { com o } \\
\text { compartilhamento de } \\
\text { redes }\end{array}$ & $\begin{array}{l}\text { Operadoras de } \\
\text { Telecomunicações } \\
\text { no Brasil }\end{array}$ & SIMPOI \\
\hline $\begin{array}{c}\text { Lübeck, } \\
\text { Wittmann, } \\
\text { Battistella e } \\
\text { Schendler (2011) }\end{array}$ & UFSM & $\begin{array}{l}\text { Ganhos de escala e } \\
\text { poder de Mercado, } \\
\text { aprendizagem e } \\
\text { inovação, redução de } \\
\text { custo e risco }\end{array}$ & $\begin{array}{l}3 \text { Empresas de } \\
\text { Transporte Público } \\
\text { no Rio Grande do } \\
\text { Sul }\end{array}$ & 3 E's - ANPAD \\
\hline $\begin{array}{l}\text { Gaio, Duclós e } \\
\text { Amaral (2012) }\end{array}$ & PUC/PR & $\begin{array}{l}\text { Associação de } \\
\text { Instituições de Ensino }\end{array}$ & $\begin{array}{l}\text { Centro Universitário } \\
\text { Católico de Santa } \\
\text { Catarina }\end{array}$ & $\begin{array}{c}\text { Revista Gestão Universitária } \\
\text { na América Latina }\end{array}$ \\
\hline
\end{tabular}

Quadro 3 - Pesquisas publicadas no Brasil

Fonte: Elaborado pelos autores.

Nos 26 trabalhos listados no Quadro 3 encontram-se 55 autores e co-autores diferentes, das mais diversas instituições do país. Destacam-se os autores vinculados as universidades do sul do país (Rio Grande do Sul, Santa Catariana e Paraná), do sudeste (São Paulo, Rio de Janeiro e Minas Gerais), e nordeste (Ceará, Fortaleza e Pernambuco). A pesquisa encontrou textos publicados em anais de congresso (12), revistas eletrônicas (9) e também dissertações de mestrado disponíveis online (5).

Os trabalhos utilizaram objetos de estudos em diversos setores da economia, como: tecnologia da informação e comunicações, bebidas e alimentos, calçados e vestuários, companhias aéreas, instituições bancárias, farmacêuticos, agropecuários, transportes, e até instituições de ensino.

No Quadro 4 são apresentados os autores mais citados nos textos publicados em português por pesquisadores brasileiros, aparecem como autores mais citados nesses textos e não aparecem como mais citados nos artigos internacionais: Dagnino e Padula (2002), Porter (1989, 1990 e 1999), Gulati (1998), Amato Neto (2000), Yin (2001), Balestrin e Vargas (2004), Leão (2004), Mintzberg, Ahlstrand e Lampel (2000), Nohria e Eccles (1992), Brandenburger e Nalebuff (1995), Gulati, Nohria e Zaheer (2000), Jarillo (1988) e Lorange e Ross (1996). 
Identificação dos Principais Autores em Coopetição

\begin{tabular}{|c|c|c|}
\hline AUTORES & QTDE & $\%$ \\
\hline DAGNINO, G. B. e PADULA, G., 2002 & 13 & 1,72 \\
\hline LADO, A. A.; BOYD, N. G. e HANLON, S. C., 1997 & 12 & 1,59 \\
\hline NALEBUFF, B. J e BRANDENBURGER, A. M., 1996 & 11 & 1,46 \\
\hline BENGTSSON, M. e KOCK, S., 2000 & 9 & 1,19 \\
\hline PORTER, M. E., 1999 & 9 & 1,19 \\
\hline GULATI, R., 1998 & 8 & 1,06 \\
\hline AMATO NETO, J., 2000 & 7 & 0,93 \\
\hline PORTER, M. E., 1989 & 7 & 0,93 \\
\hline YIN, R. K., 2001 & 7 & 0,93 \\
\hline BALESTRIN, A. e VARGAS, L. M. 2004 & 6 & 0,79 \\
\hline CASAROTTO FILHO, N. e PIRES, L. H., 1999 & 6 & 0,79 \\
\hline LEÃO, D. A. F. S., 2004 & 6 & 0,79 \\
\hline MINTZBERG, H.; AHLSTRAND B. e LAMPEL J., 2000 & 6 & 0,79 \\
\hline NOHRIA, N. e ECCLES, R., 1992 & 6 & 0,79 \\
\hline BENGTSSON, M. e KOCK, S., 1999 & 6 & 0,79 \\
\hline BRANDENBURGER, A. M. e NALEBUFF, B. J., 1995 & 5 & 0,66 \\
\hline DYER, J. H.; SINGH, H., 1998 & 5 & 0,66 \\
\hline GULATI, R.; NOHRIA, N. e ZAHEER, A, 2000 & 5 & 0,66 \\
\hline HAMEL, G.; DOZ, Y. L. e PRAHALAD, C. K., 1989 & 5 & 0,66 \\
\hline
\end{tabular}


Valdir Antonio Vitorino Filho, Eliciane Maria da Silva, João Batista de Camargo Júnior \& Silvio Roberto Ignácio Pires

\begin{tabular}{|l|c|c|}
\hline JARILLO, J .C., 1988 & 5 & 0,66 \\
\hline LORANGE, P. e ROSS, J., 1996 & 5 & 0,66 \\
\hline PORTER, M. E., 1990 & 5 & 0,66 \\
\hline WILLIAMSON, O E., 1985 & 5 & 0,66 \\
\hline
\end{tabular}

Quadro 4 - Autores mais citados em textos brasileiros

Fonte: Elaborado pelos autores com base nos dados da pesquisa.

Foram encontradas 756 citações, sendo que 582 citações aparecem apenas uma vez, 100 citações com duas ocorrências, 41 citações com três ocorrências, 13 citações com quatro ocorrências, 8 citações com cinco ocorrências, 6 citações com seis ocorrências, 3 citações com sete ocorrências, 1 citação com oito ocorrências e 2 citações com nove ocorrências.

Como autores mais citados (mais de dez citações) encontram-se: Dagnino e Padula (2002) com treze citações, Lado, Boyd e Hanlon (1997) com doze citações, Nalebuff e Brandenburger (1996) com onze citações.

Verificou-se que dentre os autores mais citados constam obras de autores brasileiros como, por exemplo: Amato Neto (2000), Balestrin e Vargas (2004), Casarotto Filho e Pires (1999) e Leão (2004).

Destacam-se ainda, os três trabalhos de Porter (1989, 1990 e 1999) entre as referências mais citadas. O autor Yin (2001) como um autor considerado metodológico, e utilizado como referência entre diversos trabalhos, aparecendo como um dos mais citados nas pesquisas em coopetição, para formulação dos métodos e das técnicas de pesquisa utilizados nos textos.

Dos autores relacionados no Quadro 5, como os mais citados nos textos brasileiros sobre coopetição, as suas respectivas obras versam sobre temas que vão de aplicações e modelos relacionados diretamente com coopetição (Hamel, Doz e Prahalad, 1989; Brandenburger e Nalebuff, 1995; Nalebuff e Brandenburger, 1996; Lado, Boyd e Hanlon, 1997; Bengtsson e Kock, 1999 e 2000; e Leão, 2004). Um autor de metodologia em pesquisa, especificamente em estudos de caso (Yin, 2001). Temas relacionados à vantagem competitiva, dependência de recursos e estratégias de competição (Williamson, 1985; Poter, 1989, 1990 e 1999; e Mintzberg, Ahlstrand e Lampel, 2000). Os estudos em redes de empresas, alianças estratégicas e redes de cooperação 
Identificação dos Principais Autores em Coopetição

(Jarillo, 1988; Nohria e Eccles, 1992; Lorange e Ross, 1996; Dyer e Singh, 1998; Casarotto Filho e Pires, 1999; Amato Neto, 2000; Gulati, Nohria e Zaheer, 2000; e Balestrin e Vargas, 2004)

Os autores que aparecem como os mais citados entre os trabalhos dos pesquisadores nacionais e internacionais são: Bengtsson e Kock (1999, 2000), Nalebuff e Brandenburger (1996), Lado, Boyd e Hanlon (1997), Hamel, Doz e Prahalad (1989), Dyer e Singh (1998) e Williamson (1985). Como demonstra o Quadro 5.

\begin{tabular}{|l|}
\hline AUTORES MAIS CITADOS EM COMUM (NÍVEL INTERNACIONAL E NÍVEL BRASIL) \\
\hline BENGTSSON, M. e KOCK, S., 1999 \\
\hline NALEBUFF, B. J e BRANDENBURGER, A. M., 1996 \\
\hline LADO, A. A.; BOYD, N. G. e HANLON, S. C., 1997 \\
\hline HAMEL, G.; DOZ, Y. L. e PRAHALAD, C. K., 1989 \\
\hline BENGTSSON, M. e KOCK, S., 2000 \\
\hline DYER, J. H. e SINGH, H., 1998 \\
\hline WILLIAMSON, O. E., 1985 \\
\hline
\end{tabular}

Quadro 5 - Autores mais citados em comum

Fonte: Elaborado pelos autores com base nos dados da pesquisa.

Sendo os autores considerados "clássicos" sobre o tema coopetição: Hamel, Doz e Prahalad (1989) com o artigo intitulado "Collaborate With Your Competitors and Win", Nalebuff e Brandenburger (1996) com o livro "Co-opetition", Lado, Boyd e Hanlon (1997) com o artigo "Competition, Cooperation, and the Search for Economic Rents: a syncretic model", e Bengtsson e Kock (1999 e 2000) com os artigos "Cooperation and competition in relationships between competitors in business networks" e "Coopetition in Business Networks - to Cooperate and Compete Simultaneously", respectivamente.

E ainda, temas relacionadas à coopetição, como a abordagem sobre estratégias cooperativas e fontes de vantagem competitiva interorganizacionais (Dyer e Singh, 1998). E as instituições econômicas do capitalismo, onde o mercado é apropriado para conduzir transações quando todas as informações necessárias às partes são traduzidas pelo mecanismo do preço (Williamson, 1985). 


\section{CONSIDERAÇÕES FINAIS}

O entendimento entre as empresas é importante para o desenvolvimento de proposições separadas entre a competitividade e a parte cooperativa, para a divisão e gerenciamento. (BENGTSSON E KOCK, 2000). A coopetição vem a ser uma extensão da rede de empresas, onde os concorrentes ativamente trabalham juntos para criar algo que não poderiam realizar sozinhos. (BAGSHAW e BAGSHAW, 2001).

Sobre as aplicações em coopetição pode-se dizer que são inúmeras para as empresas, e que derivam essencialmente da aplicação de sinergias distintas em partes do processo, podendo ser: um aumento na capacidade de produção, a busca por redução dos esforços de investimentos, maior capacidade de flexibilidades nos processos produtivos, maiores investimentos em pesquisa, desenvolvimento e inovações tecnológicas, a racionalização dos canais de distribuição, a possibilidade de acesso a novos mercados, dentre outras atividades. Tendo por outro lado alguns riscos, como: as dificuldades no entendimento dos direitos e obrigações entre as empresas, a falta de “espírito cooperativo", os risco na exposição do seu know-how para outras empresas.

Para o objetivo da pesquisa "identificar os principais autores em coopetição", pode-se afirmar que foi alcançado, porque tantos nas pesquisas bibliográficas internacionais e nacionais os autores mais citados são os considerados "clássicos" no tema, os autores Hamel, Doz e Prahalad (1989); Nalebuff e Brandenburger (1996); Lado, Boyd e Hanlon (1997); e Bengtsson e Kock (1999 e 2000).

Para as questões de pesquisa elaboradas: "quais as referências mais citadas no Brasil e no mundo em estudos sobre coopetição?", foi respondida e as referências são destacadas durante o texto (ver Figura 6 e Quadro 4). E para a questão de pesquisa "existe uma padronização ou homogeneidade das referências bibliográficas mais citadas em estudos de coopetição com relação a pesquisas no Brasil e no exterior?", e para os pressupostos de pesquisa "há claramente alguns autores com maior número de citações para as pesquisas sobre coopetição" e "os pesquisadores brasileiros utilizam as mesmas citações que os pesquisadores da comunidade internacional”, podese dizer que dentre os 23 autores mais citados nos textos internacionais e os dos 23 autores mais citados nos textos em nível Brasil, existem 6 citações em comum entre as mais citadas (Ver Quadro 5), e dos mais citados em textos brasileiros 5 citações são textos de origem nacional.

Para o pressuposto "nas publicações internacionais, há claramente um crescente número de publicações durante a evolução dos anos”, pode-se dizer que foi confirmado, pois, no ano de 1996 encontraram-se 3 publicações e em 2009 e 2011 foram 12 publicações em cada ano. 
No pressuposto da pesquisa "nas pesquisas internacionais e nacionais existe claramente autores com maior número de publicações na área", não pode ser confirmado, pois dentre as 65 publicações internacionais, dois pesquisadores apareceram como autores ou co-autores de artigos de três artigos (Eriksson, Per-Erik e Luo, Y.). E nos 26 textos publicados nacionalmente destacam-se as pesquisa de Winckler, sendo autora ou co-autora de quatro textos e interagindo com sete autores diferentes.

A presente pesquisa limita-se devido a não abrangência de todos os artigos publicados disponíveis nas bases de dados internacionais, apesar dos poucos artigos publicados sobre o tema, o que sugere a possibilidade de análises complementares. E ainda, em nível Brasil, a pesquisa limitou-se a utilizar como palavra-chave para busca nos artigos a palavra "coopetição", podendo a amostra ser ampliada para pesquisa em palavras-chave como "alianças", "cooperação e competição", entre outras, para uma maior abrangência envolvendo o tema. Nesse contexto, tanto com a formação de um comparativo, como a ampliação da amostra poderia proporcionar generalizações mais precisas sobre coopetição e a abordagem em separado dos temas cooperação e competição e seus correlatos.

\section{REFERÊNCIAS}

Alves, P. V. dos S. (2010) O Estado como uma Tecnologia: uma Visão da Evolução do Estado por Meio da Coopetição e dos Ciclos de Hegemonia e de Tecnologia. Revista do Mestrado em Administração e Desenvolvimento Empresarial, v. 14, n. 3, p. 9-27.

Amato Neto, J. (2000) Redes de cooperação produtiva e clusters regionais: oportunidades para as pequenas e médias empresas. São Paulo: Atlas.

Azevedo, J. R. de; Matos, F. R. N. (2006) Cooperação e competição simultânea em uma rede de negócios: a coopetição na Valexport. In: XII SIMPEP, Bauru-SP.

Bagshaw, M.; Bagshaw, C. (2001) Co-opetition applied to training: a case study. Industrial and Commercial Training, v. 33, n. 5, p. 175-177.

Balestrin, A. Vargas, L. M. (2004) A Dimensão Estratégica das Redes Horizontais de PMEs: Teorização e Evidências. Revistas de Administração Contemporânea. Edição Especial, p. 203. 
Valdir Antonio Vitorino Filho, Eliciane Maria da Silva, João Batista de Camargo Júnior \& Silvio Roberto Ignácio Pires

Barney, J. (1991) Firm resources and sustained competitive advantage. Journal of Management, 17, p. $99-120$.

Bengtsson, M.; Kock, S. (1999) Cooperation and competition in relationships between competitors in business networks. The Journal of Business \& Industrial Marketing. v. 14, n. 3, p. 178-194.

Bengtsson, M.; Kock, S. (2000) Coopetition in Business Networks - to Cooperate and Compete Simultaneously. Industrial Marketing Management 29, p. 411-426.

Brandenburger, A. M.; Nalebuff, B. J. (jul/ago. 1995) The right game: Use of game theory to shape strategy, Harvard Business Review, p.57-81.

Casarotto Filho, N.; Pires, L. H. (1999) Rede de pequenas e médias empresas e o desenvolvimento regional. São Paulo: Atlas.

Chen, M. (1996) Competitor analysis and interfirm rivalry: toward a theoretical integration. Academy of Management Review, n. 21, p. 100-134.

Collins, J.; Hussey, R. (2005) Pesquisa em Administração. Porto Alegre: Bookman.

Costa, E. A. da; Bottura, C. P.; Boaventura, J. M. G.; Fischann, A. A. (2006) Expansão do Conceito de Co-Opetição e sua Aplicação para Análise dos Jogos Estratégicos na Indústria de PCs. Anais do XXX Encontro Nacional da Associação Nacional de Pós-Graduação e Pesquisa em Administração - ANPAD - Set.

Dagnino, G. B.; Padula, G. (2002) Coopetition Strategy: a new kind of interfirm dynamics for value creation. In: II Annual Conference of Euram on: "Innovative Research Management". Track: "Coopetition Strategy: Towards a new kind of interfirm dynamics". Stockholm: may 9-11.

Dyer, J. H.; Singh, H. (1998) The Relational View: Cooperative Strategy and Sources of Interorganizational Competitive Advantage. Academy of Management Review, v.23, n. 4, 660679.

Gaio, J.; Duclós, L. C.; Amaral, H. G. (2012) Relevância da Estratégia de Coopetição para as IES: O posicionamento do Centro Universitário Católico de Santa Catarina. Revista Gestão Universitária na América Latina, v. 5, n.2, p. 36-57.

Gyawalli, D. R; Madhavan, R. (2001) Cooperative Networks and Competitive Dynamics: a structural embeddedness perspective. Academy of Management Review, v.26, n. 3, p.431-445.

Gnyawali, D. R.; Park, B. J. (2009) Co-opetition and Technological Innovation in Small and Medium-Sized Enterprises: A Multilevel Conceptual Model. Journal of Small Business Management, 47(3), p. 308-330. 
Gollo, S. S. (2006) Framework para Análise das Inovações e das Estratégias de Cooperação Competitiva - Coopetição: Estudo de Caso da Indicação de Procedência Vale dos Vinhedos Serra Gaúcha/RS. XXX Encontro Nacional da Associação Nacional de Pós-Graduação e Pesquisa em Administração - ANPAD - Set.

Gollo, S. S.; Castro, A. W. V. de. (2008) O processo de inovação e de estratégias de cooperação competitiva para a obtenção da indicação de procedência vale dos vinhedos: O caso da vinícola Boutique Lidio Carraro - Serra Gaúcha-RS. Congresso da Sociedade Brasileira de Economia, Administração e Sociologia Rural.

Gollo, S. S.; Setubal, J. B.; Cruz, C. M. L.; Winckler, N. C.; Rodrigues, R. G. (2008) O processo de inovação e de estratégias de cooperação competitiva para a obtenção da indicação de procedência Vale dos Vinhedos: O caso da vinícola Valduga/Serra Gaúcha/RS. Congresso da Sociedade Brasileira de Economia, Administração e Sociologia Rural.

Granovetter, M. (1985) Economic Action and Social Structure: The Problem of Embeddedness. The American Journal of Sociology, v. 91, n. 3, p. 481-510, 1985.

Gulati, R. Alliances and networks. Strategic Management Journal, v. 19, p. 293-317.

Gulati, R.; Nohria, N.; Zaheer, A. (2000) Strategic Networks. Strategic Management Journal, v. 21, p. 203-215.

Hamel, G. (1991) Competition for competence and Inter-Partner Learning within International Strategic Alliances. Strategic Management Journal, v. 12, p. 83-103.

Hamel, G; Doz, Y. L.; Prahalad, C. K. (jav/feb. 1989) Collaborate With Your Competitors and Win. Harvard Business Review, v. 72, n.4, p.133-139.

Jarillo, J. C. (1988) On strategic networks. Strategic Management Journal, v. 9, n. 1, p. 31-41.

Khanna, T; Gulati, R.; Nohria, N. (1998) The dynamics of learning alliances: competition, cooperation and relative cope. Strategic Management Journal, v.19, n.3.

Lado, A. A.; Boyd, N. G.; Hanlon, S. C. (1997) Competition, Cooperation, and the Search for Economic Rents: a syncretic model. Academy of Management Review, n.1, p.110-141.

Leão, D. A. F. de S. (2004) Coopetição: Tipologia e Impactos no Desempenho das Empresas da Indústria de Cachaça de Alambique do Estado de Minas Gerais. Universidade Federal de Pernambuco, Programa de Pós Graduação em Adminsitração. (Dissertação de Mestrado).

Leite, R. S.; Lopes, H. E. G.; Silva, S. A. D. (2009) A estratégia em relacionamentos coopetitivos: um estudo do arranjo produtivo de Nova Serrana. Revista Brasileira de Gestão de Negócios, v. 11, n. 30, p. $65-78$. 
Valdir Antonio Vitorino Filho, Eliciane Maria da Silva, João Batista de Camargo Júnior \& Silvio Roberto Ignácio Pires

Lin, C. P.; Wang, Y. J.; Tsai, Y. H.; Hsu, Y. F. (2010) Perceived job effectiveness in coopetition: A survey of virtual teams within business organizations. Computers in Human Behavior, v. 26, p. 1598-1606.

Lorange, P.; Ross, J. (1996) Alianças estratégicas: formação, implementação e evolução. São Paulo: Atlas.

Lubeck, R., M.; Wittmann, M., L.; Battistella, L., F.; Schendler, S., G. (2011) Coopetição: os fatores competitivos aplicados a redes de empresas de transporte público. V Encontro de Estudos em Estratégia, Porto Alegre-RS.

Luo, X. M. (2006) Cross-Functional Coopetition: The Simultaneous Role of Cooperation and Competition within Firms. Journal of Marketing, v. 70, n. 2.

Luo, Y. (2004) Toward coopetition within a multinational enterprise: a perspective from foreign subsidiaries. Journal of World Business, v. 40, p. 71-90.

Marchi, J., J.; Wittmann, M., L. (2008) Redes de Empresas: Uma análise das relações entre fatores sócio-comportamentais e desempenho competitivo. REAd, v. 14, n. 2.

Melo, D., B. de. (2009) Análise da Rede de Valor Voltada para os Negócios Internacionais: estudo de caso da empresa líder do setor de calçados do Ceará. Universidade de Fortaleza-UNIFOR, Fortaleza-CE. (Dissertação de Mestrado).

Melo, R. S de; Câmara, S. F.; Galindo, A. G.; Capelo Jr, E.; Rocha, C. A. S. R. (2008) Análise das Estratégias de Investimentos em P\&D nas Empresas de Tecnologia da Informação e Comunicação à Luz da Teoria dos Jogos: o caso do Instituto Titan, em Fortaleza-CE. Anais do XXXII Encontro Nacional da Associação Nacional de Pós-Graduação e Pesquisa em Administração - ANPAD - Set.

Mintzberg, H.; Ahlstrand, B.; Lampel, J. (2000) Safári de estratégia: um roteiro pela selva do planejamento estratégico. Trad. de Nivaldo Montingelli Jr. Porto Alegre: Bookman.

Morgan, R. M. (jul. 1994) The Commitment-Trust Theory of Relationship Marketing. Journal of Marketing, v. 58; p. 20-38.

Nalebuff, B. .J; Brandenburger, A. M. (1996) Co-opetição. Rocco: Rio de Janeiro.

Neves, M., P. S. das. (2009) Análise da Coopetição em Redes Horizontais de Pequenas e Médias Empresas do RS na Percepção dos Gestores das Redes. Pontifícia Universidade Católica do Rio Grande do Sul, Porto Alegre. (Dissertação de Mestrado). 
Neves, M. P. S. das; Diehl, C. A.; Hansen, P. B.; Becjer, G. V. (jul/set. 2011) Análise do Processo de Coopetição em Redes Horizontais de Pequenas e Médias Empresas do Rio Grande do Sul. Revista de Administração e Contabilidade da Unisinos, v. 8, n. 3, p. 243-260.

Nohria, N. Eccler, R. G.(Orgs). (1992) Networks and organizations: structure, form and action. Boston: Harvard Business School Press, Massachusetts, p. 1-22.

Oliveira, U., R. de; Marins, F. A. S.; Rocha, H, M. (out. 2006) Estratégia de coopetição versus competências essenciais e prioridades competitivas em gestão de operações: análise do consórcio modular da Volkswagen Caminhões e Ônibus do Brasil. XXVI ENEGEP - Fortaleza, CE, Brasil.

Pfeffer, J.; Salancik, G. (1978) The External Control of Organizations: A Resource Perspective. Harper \& Row, New York.

Petter, R. R.; Vaz, C. R.; Resende, L. M. M. de; Francisco, A. C. de. (set. 2011) Coopetição Sistêmica de Redes Interorganizacionais: Um Modelo Estrutural. Congresso Internacional de Administração - Gestão Estratégica: Inovação Colaborativa e Competitividade.

Porter, M. E. (1989) Vantagem competitiva: criando e sustentando um desempenho superior. Rio de Janeiro: Campus.

Porter, M. E. (1990) The competitive advantage of nations. Harvard Business Review, mar-apr, p. 73-91.

Porter, M. E. (1999) Competição - On Competition: Estratégias Competitivas Essenciais. 16 ed., 515 p. Elsevier: São Paulo.

Pritchard, A. (1969) Statistical Bibliography or Bibliometrics? Journal of Documentation, v. 25, n. 4, pp. 348-349.

Quintana-Garcia, C.; Benavides-Velasco, C. A. (2004) Cooperation, competition and innovative capability: a panel data of European dedicated biotechnology firms. Technoinovation, n. 20, p. 112 .

Rennó, T., M.; Judice, V., M., M. (2008) Relações interorganizacionais em rede de franquias: cooperação, coexistência, competição, coopetição em uma rede de serviços educacionais em Belo Horizonte. Revista de Administração da FEAD-Minas, v. 5.

Rodrigues, L. C.; Maccari, E. A.; Riscarolli, V. (2007) Arquitetura e Coopetição em Redes Interorganizacionais. Revista de Gestão da Tecnologia e Sistemas de Informação, v. 4, n. 2, p. 175-196. 
Valdir Antonio Vitorino Filho, Eliciane Maria da Silva, João Batista de Camargo Júnior \& Silvio Roberto Ignácio Pires

Sauaia, A. C.; Kallás, D. (2007) O Dilema Cooperaçăo-Competiçăo em Mercados Concorrenciais: o Conflito do Oligopólio Tratado em um Jogo de Empresas. Revista de Administração Contemporânea, $1^{\mathrm{a}}$ Edição Especial, p. 77-101.

Schiavone, F.; Simoni, M. (2011) An experience-based view of co-opetition in R\&D networks. European Journal of Innovation Management, v. 14, n. 2, p. 136-154.

Schoo, P. (2009) Co-opetition Enabling Security for Cooperative Networks: Authorizing Composition Agreement Negotiations between Ambient Networks. Wireless Pers Commun, v. 49, p. 415-430.

Seloti Jr, S. L. (2008) Sensemaking em alianças estratégicas: busca, interpretação e ação. Fundação Getúlio Vargas - Escola de Administração de Empresas, São Paulo. (Dissertação de Mestrado).

Tsai, W. (2002) Social structure of coopetition within a multiunit organization: coordination, competition, and intraorganizational knowledge sharing. Organizational Science, v. 13, n. 2, p. 179-190.

Uzzi, B. (1997) Social structure and competition in interfirm networks: the paradox of embeddedness. Administrative Science Quarterly, v. 4, p. 35-67.

Walley, K. (2007) An investigation of eco-opetition between South African firms. University of Stellenbosch Business School. 20 ${ }^{\text {th }}$ EDAMBA Summer Academy.

Williamson, O. E. (1985) The Economic Institutions of Capitalism. New York: The Free Press.

Winckler, N., C. (2010) A Coopetição entre propriedades rurais da cadeira produtiva do leite no Oeste Catarinense. Universidade Federal do Rio Grande do Sul. Porto Alegre. (Dissertação de Mestrado).

Winckler, N. C.; Brandão, F. S.; Machado, J. A. D. (2010) Tomada de Decisão e Rede de Valor: o Caso de uma Propriedade Rural Familiar no Oeste Catarinense. $48^{\circ}$ Congresso SOBER Sociedade Brasileira de Economia Administração e Sociologia Rural.

Winckler, N. C.; Molinari, G. T. (2011) Competição, Colaboração, Cooperação e Coopetição: Revendo os Conceitos em Estratégias Interorganizacionais. Revista ADMpg Gestão Estratégica, v. 4 , n. 1 .

Yadong, L. (2007) A coopetition perspective of global competition. Journal of World Business, v. 42 , p. 129-144.

Yin, R. K. (2001) Estudo de caso: planejamento e métodos. $2^{\mathrm{a}}$ ed. Porto Alegre: Bookman. 
Zampese, E. R. de S.; Zilber, M. A. (2011) Estudo de Caso de Coopetição no Compartilhamento de Infra-Estrutura entre Operadoras de Telecomunicações no Brasil. SIMPOI, São Paulo-SP.

Zhang, J.; Frazier, G. V. (2011) Strategic alliance via co-opetition: Supply chain partnership with a competitor. Decision Support Systems, v. 51, p. 853-863.

Zineldin, M. (2004) Co-opetition: the organization of the future. Marketing Intelligence \& Planning, v. 22, n. 7, p. 780-789.

Recebido: 15/01/2013

Aprovado: 06/03/2013 